\title{
Automated medical surgical trolley
}

\author{
N. M. Saad ${ }^{1}$, A. R. Abdullah', N. S. M. Noor ${ }^{3}$, N. A. Hamid ${ }^{4}$, M. A. Muhammad Syahmi ${ }^{5}$ N. M. Ali ${ }^{6}$ \\ 1,3,4,5Fakulti Kejuruteraan Elektronik dan Kejuruteraan Komputer, Universiti Teknikal Malaysia Melaka, Malaysia \\ ${ }^{2}$ Fakulti Kejuruteraan Elektrik, Universiti Teknikal Malaysia Melaka, Malaysia
}

\begin{tabular}{l}
\hline \hline Article Info \\
\hline Article history: \\
Received Aug 12, 2018 \\
Revised Nov 20, 2018 \\
Accepted Dec 26, 2018 \\
\hline
\end{tabular}

Keywords:

Arduino

Automatic medical surgical

trolley movement

IP camera

Operation theatre

Surgical equipment

\begin{abstract}
Operating theatre is a place in a hospital where surgical operations are conducted on patients by surgeons. In the operating theatre, the surgical equipment is placed on stainless steel table or on surgical instrument tray. However, during the operation accidents can occur where the surgical tools placed near to the surgeon could be accidentally be hit by them during the surgical operation. This may cause the surgical tools to fall on the floor which may lead to injuries. Hence, this paper presents an automatic medical surgical trolley for surgeons to grab operating tools easily. The proposed system is implemented for automaticmedical surgical trolley movement using Arduino Uno R3. The invention provides an automatic medical surgical trolley which comprises automatic guidance, a wireless controller, an obstacle avoiding detection device, a touch screen controller via smart phone, an IP camera, a trolley, an integrated power supply and a processor. The trolley with stainless steel shelves is ideal for use in clinical environments and operation theatres. Medical equipment is loaded in the trolley, the wireless remote drives the trolley to move forwards and backwards. Automatic visual guidance is achieved via an IP camera attached to the trolley and a touch screen controller via a smart phone. A large amount of space and a large number of materials are saved, the workload of medical workers will be greatly relieved, and the working efficiency will be improved.
\end{abstract}

Copyright $\left({ }_{0} 2019\right.$ Institute of Advanced Engineering and Science. All rights reserved.

\section{Corresponding Author:}

N. M. Saad,

Fakulti Kejuruteraan Elektrik dan Kejuruteraan Komputer,

Universiti Teknikal Malaysia Melaka, Melaka, Malaysia.

Email: norhashimah@utem.edu.my

\section{INTRODUCTION}

Operating theatre is a very busy area and a very clean area which is always called as a "sterile". The surgical equipment tray is designed in order to lay all the surgical tools on it. The procedure's flow will become smoother if the equipment they need all in one easy to access on the tray. Recently, there are many careless cases occurred in the hospital for instance in the operating theatre [1], [2].

The messy condition of the operating tools on the tray and the position of the tray next to surgeon could make the surgeon feel uncomfortable and suffocating which could lead the surgeon concentration to be disturbed. Safety is one of the important things to consider especially at the workplace because without it, the serious injuries or death could take place [3]. Workers injuries could affect the quality of the company or business state due to it will cause the insurance rate increased, other employees may be distracted and the productivity will be lost due to the accident. Accidents occur is because one choosing the wrong method of procedure or due to poor execution [4], [5].

Accidents can occur anytime and anywhere such as in the operating theatre. For instance, the usual cases happened in the operating room are anesthesia mistakes, operations on the wrong side of the body part and the surgical tools left inside patient's body which lead to loss of a patient's life [6]. The injuries not only 
could happen to patients but to surgeons and other people inside the operating room as well. For example, the surgical tools placed near to surgeon could be accidentally be hit by them during surgical operation.

Many researchers have studied on smart trolley but many have been applied in supermarket. Reference [7] proposed smart trolley in mega mall where the component used are optical sensor as the sensor to detect obstacles and AtmelAT89V51 microcontroller. Reference [8] proposed smart trolley using RFID to speed up the purchase of product. The smart trolley will detect the items using tag card and the tag card will send information about the total price to the counter during payment.

Reference [9] proposed a smart trolley follower that follows and track line using vision based technique. The component used in this project is the ATmega microcontroller and blobbing technique as the tracking and detecting sensor. Reference [10] proposed a trolley that follows customer during shopping activities. The component used is the IR transmitter, IR receiver with a microcontroller. Reference [11] proposed a shopping trolley that can follow customer during shopping with giving information of the item located in the mall. The component proposed are the Arduino Mega as a microcontroller with ultrasonic sensor as the object detector. The RFID technology and Bluetooth module are proposed as the receiver for the instructor.

In this paper, automatic medical surgical trolley movement is designed to assist the surgeon and nurse in the operation theatre. This project involved the implementation of hardware and software design. The Arduino Uno R3 is implemented as the microcontroller for the hardware design that control the input and output instruction. Ultrasonic sensor is used as the obstacles detector to avoid trolley collide with object during the movement. Power window motor is used as the movement component in this project. The IP camera with Wi-Fi module is applied as a monitor system for the nurse to put medical equipment during the surgery is conducted.

This paper contains five section. Section 2 proposed the flow process of the proposed methodology in detail. Section 3 discussed the result of the implementation of hardware and software development toward the automatic medical surgical trolley and Section 4 conclude the work presented.

\section{RESEARCH METHOD}

\subsection{Proposed method}

The flow process of this automatic medical surgical trolley involved the implementation of hardware and software development is shown in Figure 1. The flow process begin with the input signal is transmitted to the Arduino Uno R3. The input signal transfer information to the Arduino and then transfer to the relay to give output to the power window motor. Once the signal is received, the automatic medical surgical trolley starts to move according to the instruction given. The power window motor will move the trolley backward or forward based on the ultrasonic sensor. Once the ultrasonic sensor detect object in front of it, it will stop moving until another path is recognized. Then the trolley will start move. Otherwise it will just move until it reach the location given by the instructor.

\subsection{Hardware implementation}

A hardware implementation is used that includes battery, wireless switch, smartphone, control unit, Arduino Uno R3, Relay, Ultrasonic sensor and motor. Figure 2 below shows the system architecture of this project. The system architecture used consists the power supply to power up the control unit. The wireless switch and smartphone is used as to send information to the control unit. The control unit will control the movement of the trolley based on the object detector, relay and motor. Table 1 shows the parameter and description for the project proposed.

\subsection{Arduino uno R3}

Arduino is widely used as an open-source single-board microcontroller for the development platform which is flexible, easy-to-use hardware and software components [12]. In this study, Arduino Uno R3 with an onboard USB to serial chip is used to load code into on-board Atmega328 Microcontroller. This Arduino contains everything needed to support the microcontroller. To get started, user simply needs to connect Arduino Uno R3 to a computer with a USB cable. The Arduino consist 14 digital input/output pins which is used as a PWM outputs, 6 analog inputs, $6 \mathrm{MHz}$ crystal oscillator, a USB connection, a power jack an in-circuit system programming (ICSP) header and a reset button. The pin Connection of Arduino UNO R3 with Other Hardware as shown in Table 2. 


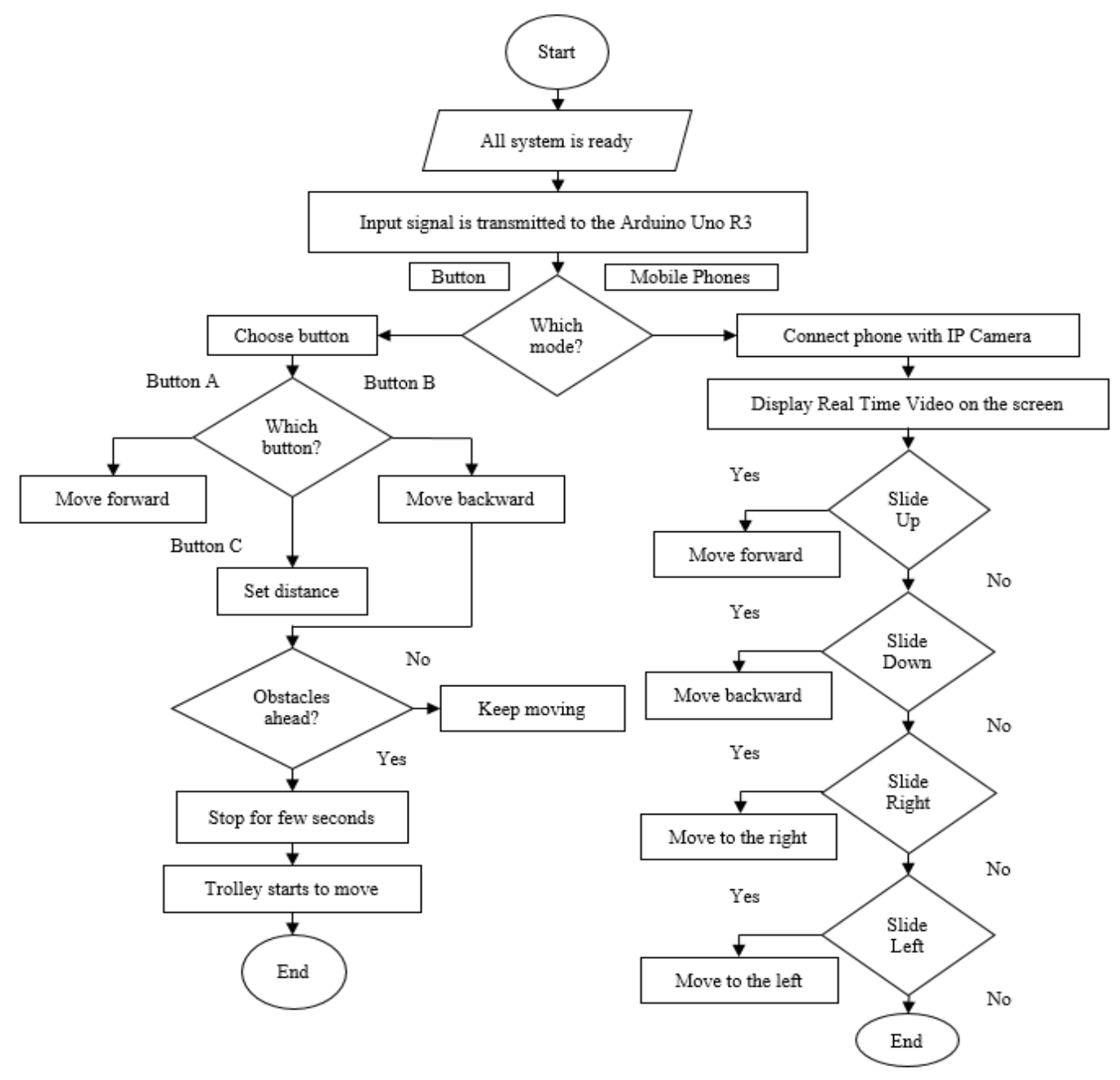

Figure 1. Proposed system design

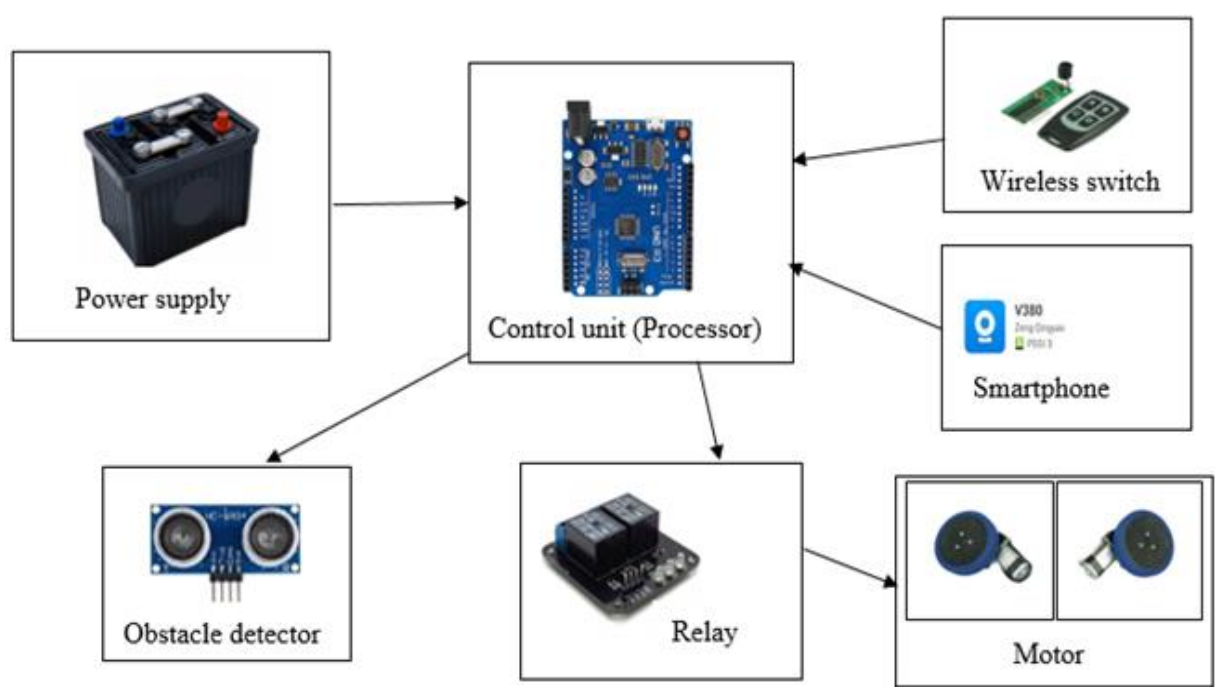

Figure 2. System architecture 
Table 1. The Parameter and Description of Automatic Medical Surgical Trolley

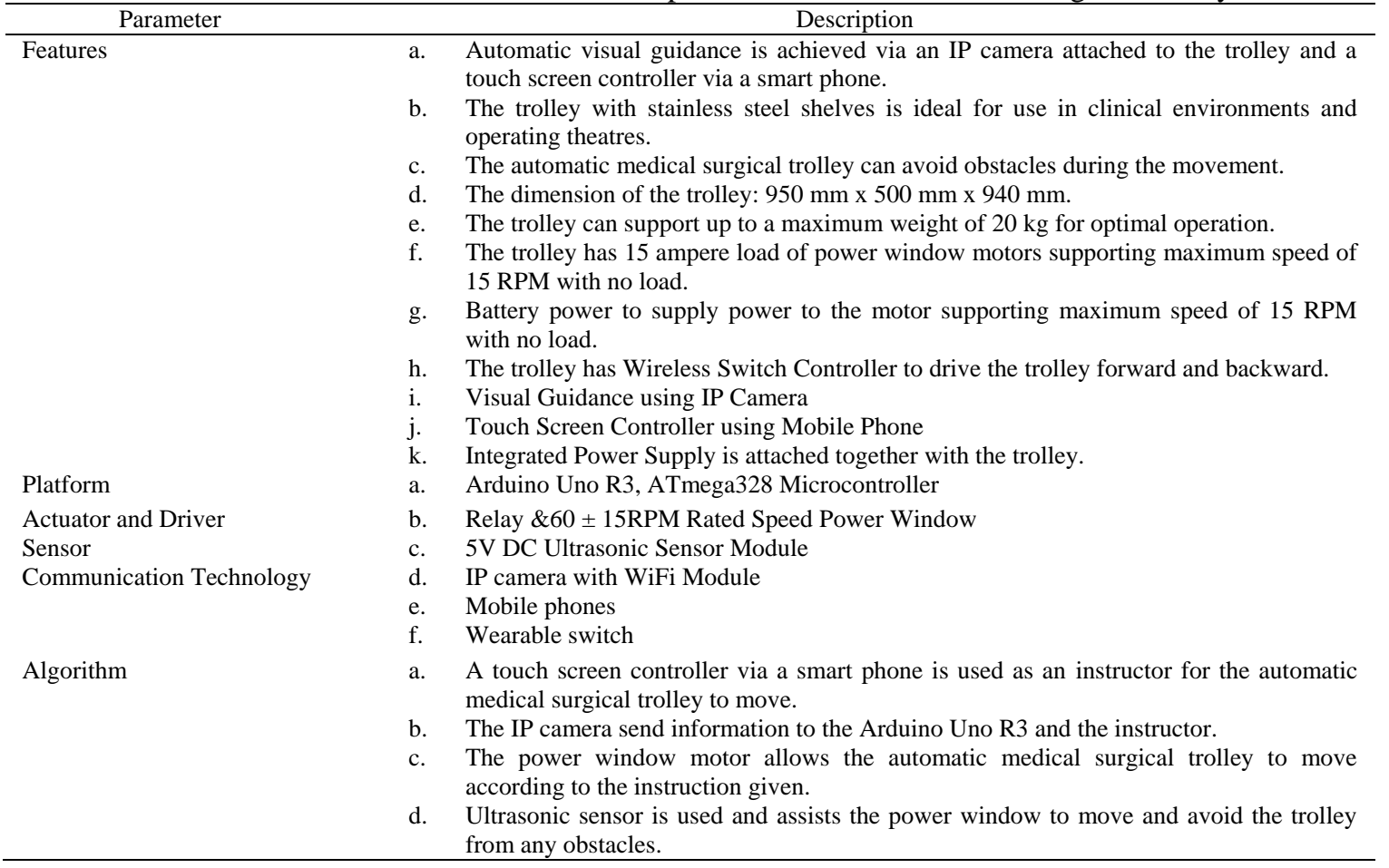

Table 2. The pin Connection of Arduino UNO R3 with Other Hardware

\begin{tabular}{ll}
\hline \multicolumn{1}{c}{ Arduino Uno R3 } & \multicolumn{1}{c}{ Output } \\
\hline pinA0 (6x Analog IN) & Resistor R1 \\
pinA1 (6x Analog IN) & Resistor R2 \\
pinA2 (6x Analog IN) & Resistor R3 \\
pinA3 (6x Analog IN) & Resistor R4 \\
pin13 (14xDigital IN/OUT) & Ultrasonic sensor 1 \\
pin12 (14xDigital IN/OUT) & Ultrasonic sensor 1 \\
pin11 (14xDigital IN/OUT) & Ultrasonic sensor 2 \\
pin10 (14xDigital IN/OUT) & Ultrasonic sensor 2 \\
pin9 (14xDigital IN/OUT) & Relay \\
pin8 (14xDigital IN/OUT) & Relay \\
pin7 (14xDigital IN/OUT) & Relay \\
pin6 (14xDigital IN/OUT) & Relay \\
pin5 (14xDigital IN/OUT) & RF module receiver \\
pin4 (14xDigital IN/OUT) & RF module receiver \\
pin3 (14xDigital IN/OUT) & RF module receiver \\
pin2 (14xDigital IN/OUT) & RF module receiver \\
\hline
\end{tabular}

\subsection{Ultrasonic uno R3}

Ultrasonic sensors are one of the favorable complementary sensors for indoor localization due to the small size, lightweight, and low cost [13]. It is used to measure the distance to an object by using sound waves. Ultrasonic sensors measure distance from a sound wave that has been sent at a specific frequency and listening for that sound wave to bounce back. This device has a stable performance and high accuracy ranging from $2 \mathrm{~cm}$ to $450 \mathrm{~cm}$.

\subsection{Wireless switch}

The wireless switch is to transmit and receive signal. The switch powers the receiver with 3.3-10Vdc and press the buttons on matching RF key fob remote. For the operation for the wireless switch, when button A is pressed, it activates the first pin on RF module (receiver). While when B button is pressed, it activates the second pin and so on for all four buttons. This is M4 momentary type acts like a push button and $\mathrm{T} 4$ toggle type acts like an alternating toggle switch. 


\subsection{Power window}

The power window is used to open and close the motor windows by switch operation. The power window that is used has features like a car manufactured by Malaysian carmaker Proton which is Proton Wira Power Window Compatible, with voltage rating of $12 \mathrm{Vdc}$, perfect fit with 5 inches' robot wheel with just 3 screws and can utilize up to $10 \mathrm{~A}$ shield to drive the motor. The rated speed is $60 \pm 15 \mathrm{RPM}$, while no load speed is $85 \pm 15 \mathrm{RPM}$, the current with no load is less than $5 \mathrm{~A}$, rated current with load is maximum to $15 \mathrm{~A}$ and stall current when trolley is locked is maximum to $28 \mathrm{~A}$ at $12 \mathrm{~V}$. the power window rated torque is $30 \mathrm{~kg} . \mathrm{cm}(2.9 \mathrm{~N} . \mathrm{m})$ while stall torque is $100 \pm 15 \mathrm{~kg} . \mathrm{cm}(\sim 10 \mathrm{~N} . \mathrm{m})$.

\subsection{Relay}

Relay is used to detect and isolate faults on transmission and distribution lines by opening and closing circuit breakers. The function of relay is also to control a circuit by a low power signal or where several circuits must be controlled by one signal. Relay was used to switch and change contact. Relay switch is an electrically operated switch where the current flowing through the coil of the relay creates a magnetic field. This magnetic field attracts a lever and changes the switch contacts. The coil current of the relay can be off or on so the relays have two switch positions and most have double throw (changeover) switch contacts. The Input and Output Connection of Relay as shown in Table 3.

\begin{tabular}{cc} 
Table 3. The Input and Output Connection of Relay \\
\hline Input of relay & Output of relay \\
\hline Arduino Uno R3 & Relay 3 \\
Arduino Uno R3 & Relay 4 \\
Relay 3 & Relay 1 \\
Relay 4 & Relay 2 \\
Relay 1 & Motor (of power window) \\
Relay 2 & Motor (of power window) \\
\hline
\end{tabular}

\subsection{Battery power}

For instance, the proper operation of microcontrollers, depended on the voltage quality supplied to them [14]-[18]. Battery power is used to supply power to the trolley. To avoid from malfunction, the battery is set to 12-volt maximum voltage.

\subsection{IP camera with wi-fi module}

The IP camera with Wi-Fi module is used in this project to monitor the movement of the trolley. The IP camera is applied for the nurse to put medical equipment onto the medical surgical trolley while surgery is conducted [19]. In this way, the nurse can avoid interrupting the surgeon from going in and out from the operating theatre only to get any medical equipment that is needed while the operation is conducted. Figure 3 shows the apps from the smart phone to drive the trolley in real time video.

\subsection{Software implementation}

The software implementation is needed to control the Arduino Uno R3. Firstly, each command needs to be declared at the top of each coding. The first coding is declared to activate the ultrasonic sensor. Figure 4 shows the source code to power on the ultrasonic sensors. After the ultrasonic is configured successfully, the sensor will detect any obstacles in the maximum range of 400 to $500 \mathrm{~cm}$. The source code is built to the Arduino Uno R3 to control the movement of the trolley. The Arduino Uno R3 is then connected to the relay to move the motor in forward, reverse, right or left direction. This system is also designed to stop the trolley when the obstacles are detected by the sensors. Figure 5 shows the full source code of the software implementation. 


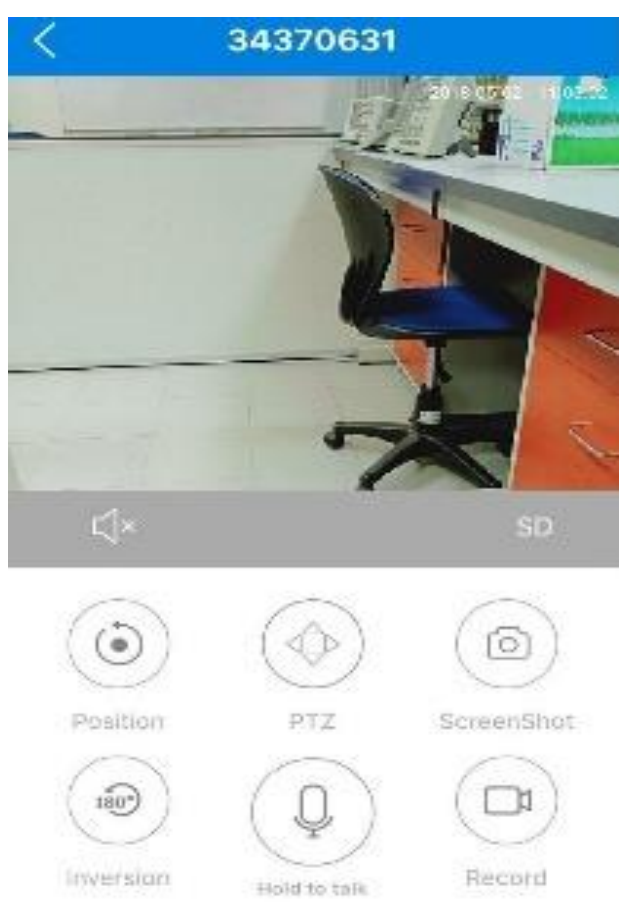

Figure 3. Apps to drive the trolley, with real-time video

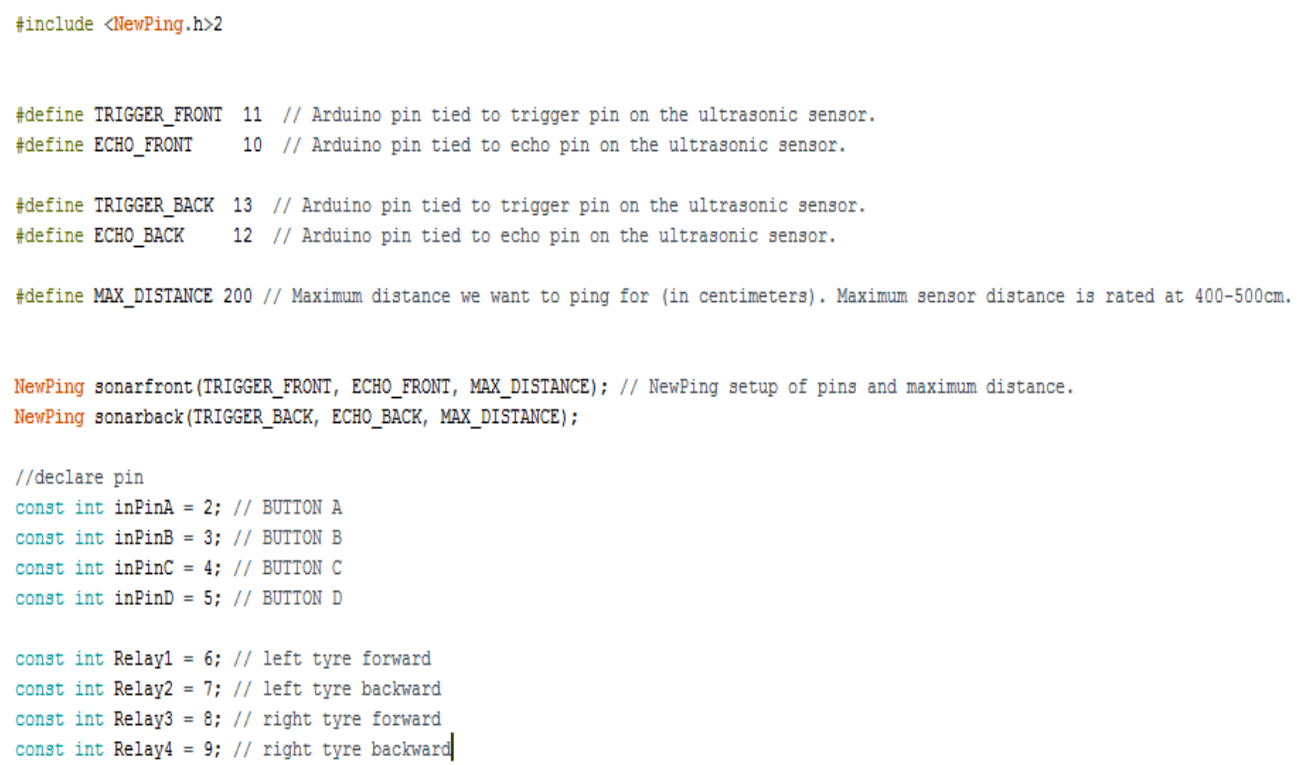

Figure 4. Source code to declare the ultrasonic sensors and wireless switch 


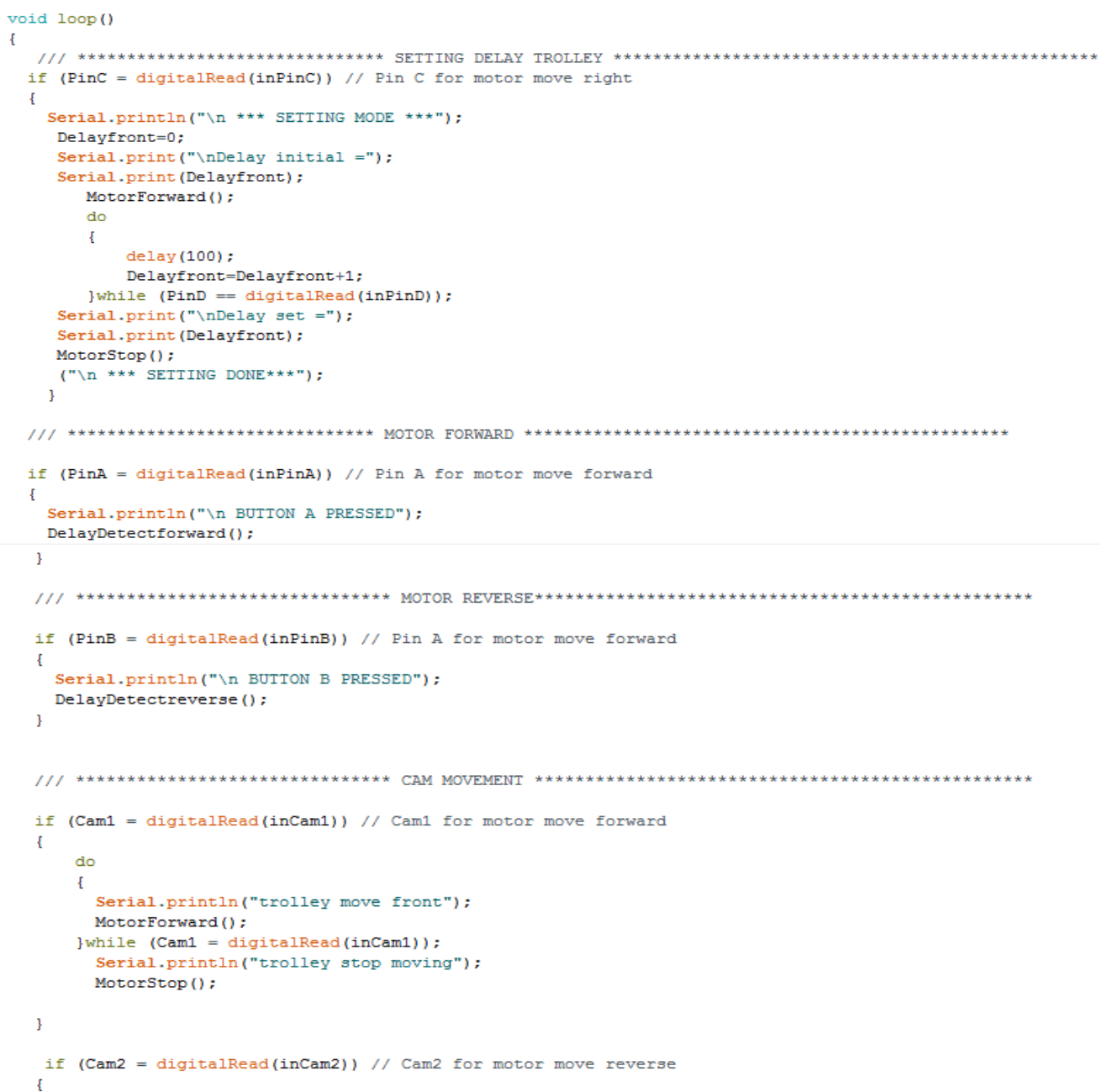

Figure 5. Source code for overall system for automatic medical surgical trolley movement

\section{RESULTS AND ANALYSIS}

Arduino Uno R3 is used as the main microcontroller to interface with all hardware used in this project. A touch screen controller via a smart phone is used as an instructor for the automatic medical surgical trolley to move. An IP camera with Wi-Fi module is used as a transmitter and receiver data between a touch screen controller to monitor the movement of automatic medical surgical trolley in and out from the operating theatre. The power window motor allows the automatic medical surgical trolley to move according to the instruction given. Thus, the automatic medical surgical trolley can lead surgeons and nurses during surgery. In order to prevent the automatic medical surgical trolley colliding with other object, ultrasonic sensors are used to avoid collision. Figure 6 shows the automatic medical surgical trolley of this project.

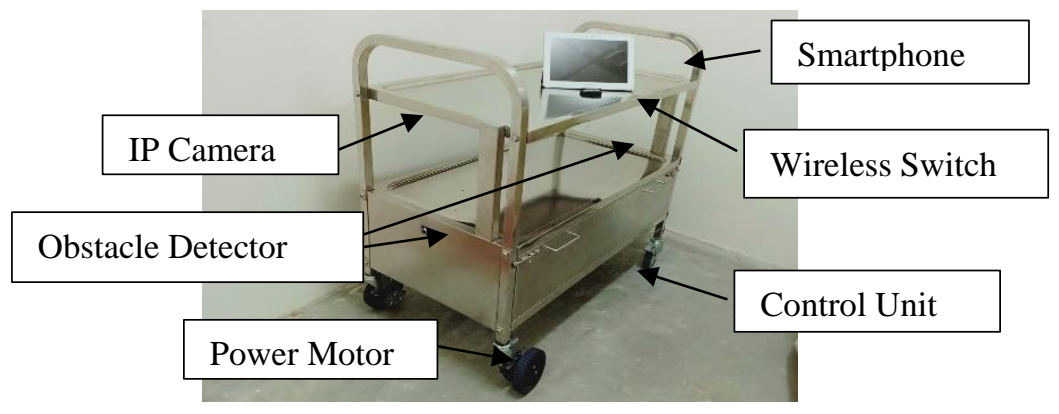

Figure 6. Automatic medical surgery movement 
The welfare of operating within any engineering environment is of the prime importance. All experiment carried out were expected in a safe manner with no negative effect on health and wellbeing. Health and safety during producing this product is about measures designed to protect the health and safety of the general public who may be affected by these activities. Product safety is a term used to describe policies designed to protect people from risks associated with thousands of consumer products they buy and use every day. Therefore, safety and health measured has always been the consideration before producing this automatic medical surgical trolley.

Arduino Uno R3 is implemented as the main controller to interface with all hardware used in this project. It is used to process the input from the instructor and transmit data to the power window. The Arduino Uno R3 is a sensitive microcontroller where several precautions must be considered. The maximum voltage applied to the Arduino Uno R3 is 5.5 volt where it does not exceed 12 volts to avoid overload voltage and it is applied on direct current only. The input and output pins were not shortening to avoid overcurrent condition on both input and output pins. The pushbuttons or switches were connected to the Arduino Uno R3 using pull up and pulldown resistor. Figure 7 shows the schematic circuit of hardware and software implementation of automatic medical surgery trolley using Proteus. The schematic includes the connection of Arduino Uno R3 to ultrasonic sensor, relays and motor.

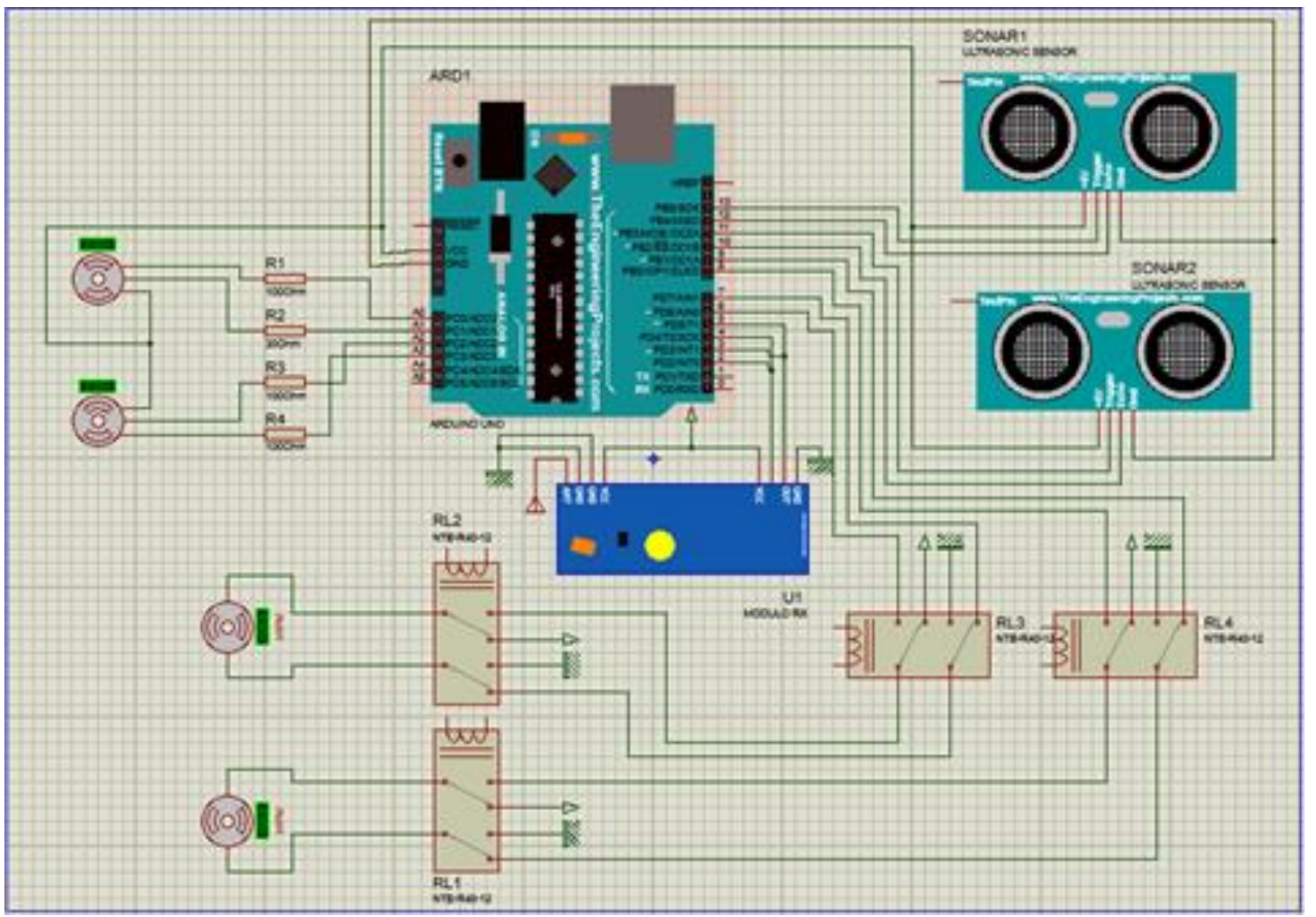

Figure 7. Schematic diagram for the hardware implementation of automatic medical surgery trolley movement

When the torque of the power window motor is decrease, inertia impact is reduced. This precaution is considered to avoid medical stuff fell down when the trolley moves and stop. The other precaution is considered is the tyre surface. The tyre surface was modified to have a higher grip so it can enable the trolley to move to the location without sliding to other place.

Several wires were used in connecting the battery with the relay and the power window motor. The end of each wire is implemented with the connector. The connectors used are made from reinforced insulation where the protection is provided by single or basic insulation but has the same protective properties as double insulation between two cables when connected. It is due to prevent from the current leakage. Thus, it can be last longer and it is a proper way to connect between two cables. 
Last but not least, the automatic medical surgery trolley is made from aluminum sterilize for protection against germs and infection. A proper hygiene is a must in health-care environment since this product will be used in hospitality environment. Aluminum is a metal use widely in hospital because its property against rust. Thus, it is easy to clean. Besides that, Food Safe Coatings for Metal applied on the trolley since the product will be used to place surgery utensils and require extra protection against germ and rust. That is especially true if you work in health care, where poor hygiene can be matter of life and death.

\section{CONCLUSION}

In conclusion, an automatic medical surgery trolley is developed to assist surgeons to reach medical equipment during surgical operation. The automatic medical surgery trolley system is developed with a microcontroller based on Atmega328 called Arduino Uno R3. The Arduino Uno R3 receive input signal and delivers output to the relay and power window motor to move the automatic medical surgery trolley. The automatic medical surgery trolley move based on the ultrasonic sensor where the sensor will move whenever no object is blocking the wat through the location. An IP camera with Wi-Fi module is attach as the monitoring system for the nurse to move the trolley in and out from the operating theatre.

\section{ACKNOWLEDGEMENTS}

The authors would like to thank the UniversitiTeknikal Malaysia Melaka (UTeM), Rehabilitation Engineering \& Assistive Technology (REAT) research group under Center of Robotics \& Industrial Automation (CeRIA), Advanced Digital Signal Processing (ADSP) Research Laboratory and Ministry of Science, Technology \& Innovation (MOSTI) Malaysia for sponsoring this work under project 06-01-14-SF00119 L00025 and the use of the existing facilities to complete this project.

\section{REFERENCES}

[1] Stahel PF., "The tenth year of the "Universal Protocol": Are Our Patients Safer Today?," Bone \& Joint 360, vol. 3, no. 1, pp.7-10, Feb 2014.

[2] Kim FJ, da Silva RD, Gustafson D, Nogueira L, Harlin T, Paul DL., "Current Issues in Patient Safety in Surgery: A Review," Patient Safety in Surgery, vol. 9, no. 1, December2015.

[3] Stefanidis D, Wang F, Korndorffer JR, Dunne JB, Scott DJ., "Robotic Assistance Improves Intracorporeal Suturing Performance and Safety in the Operating Room while Decreasing Operator Workload," Surgical Endoscopy, vol. 24, no. 2, pp. 377-820, Feb 2010.

[4] Newman-Toker DE, Pronovost PJ., "Diagnostic Errors - The Next Frontier for Patient Safety," Journal Americal Medical Association, vol. 301, no. 10, March2009.

[5] Griffen FD, Stephens LS, Alexander JB, Bailey HR, Maizel SE, Sutton BH, Posner KL., "The American College of Surgeons' Closed Claims Study: New Insights for Improving Care," Journal of the American College of Surgeons, vol. 204, no. 4, pp. 561-9, 2007.

[6] Cavallini GM, et al., "Clinical Risk Management in Eye Outpatient Surgery: ANew Surgical Safety Checklist for Cataract Surgery and Intravitreal Anti-VEGF Injection," Graefe's Archive for Clinical and Experimental Ophthalmology, vol. 251, no. 3, pp. 889-94, Mar 2013.

[7] Awati J, Awati S., "Smart Trolley in Mega Mall," International Journal of Emerging Technology and Advanced Engineering, vol. 2, no. 3. March 2012.

[8] Hanwate A, Thakare P., "Smart Trollet using RFID," International Journal of Research in Science and Engineering, pp. 2394-8299, 2015.

[9] Seema U., et al., "Smart Trolley Follower using Vision based Technique," IJCA Proceedings on National Conference on Advances in Computing, Communication and Networking ACCNET 2016, vol.7, pp. 8-10, 2016.

[10] Ali, A. A., et al.., "Follow Me Trolley," International Journal for Scientific Research and Development, vol. 22, no. 2, pp.192-193, 2014.

[11] Ng YL, et al., "Automatic HumangShopping Trolley withSmart Shopping System," JurnalTeknologi, vol. 73, no. 3, pp. 49-56, 2015.

[12] Ferdoush S and Li X., "Wireless Sensor Network System Design Using Raspberry Pi and Arduino for Environmental Monitoring Applications," Procedia Computer Science, vol. 34, pp. 103-10, Jan 2014.

[13] Zhao H and Wang Z., "Motion Measurement Using Inertial Sensors, Ultrasonic Sensors and Magnetometers with Extended Kalman Filter for Data Fusion," IEEE Sensors Journal, vol. 12, no. 5, pp. 943-53, May 2012.

[14] Abdullah AR, et al., "Power Quality Signals Classification System Using Time-Frequency Distribution," InApplied Mechanics and Material, vol. 494, pp. 1889-1894, 2014.

[15] Abdullah AR, et al., "Performance Verification of Power Quality Signals Classification System," InApplied Mechanics and Materials, Trans Tech Publications. vol. 752, pp. 1158-1163, 2015.

[16] Jopri MH, et al.., "Localization of Multiple Harmonic Sources for Inverter Loads Utilizing Periodogram," Journal of Telecommunication, Electronic and Computer Engineering (JTEC), vol. 8, no. 2, pp. 87-91, May 2016. 
[17] Habban, M.F., et al., "An Evaluation of linear time frequency distribution Analysis for VSI switch faults identification," International Journal of Power Electronics and Drive Systems (IJPEDS), vol. 8, pp. 1-9, 2017.

[18] Jopri MH, et al., "An Accurate Classification Method of Harmonic Signals in Power Distribution System by UtilisingS-Transform," Telkomnika, vol. 15, Mar 2017.

[19] Rahman NA, et al., "The Internet of Things Beverages Bottle Shape Defect Detection using Naïve Bayes Classifier," International Journal of Human and Technology Interaction (IJHaTI), vol. 2, no. 1, pp. 71-76, Apr 2018.

\section{BIOGRAPHIES OF AUTHORS}

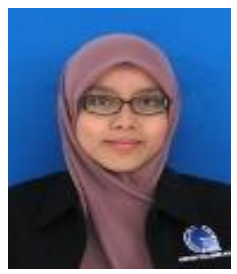

N. M. Ali received B. Eng (Hons.) (Mechatronic Engineering) from the UniversitiTeknikal Malaysia Melakain 2009 and M. Sc (Mechatronic Engineering) from UniversitiIslam Antarabangsa in 2014.She is currently pursuing $\mathrm{PhD}$ degree in Electrical Engineering at Multimedia University, Melaka. Her main research interest is in the field of image processing, intelligent system and machine learning.

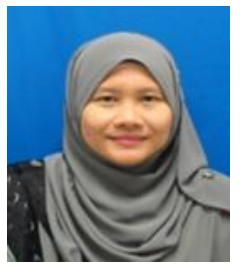

N. M. Saad is a senior lecturer at Department of Computer Engineering, Faculty of Electronics and Computer Engineering, Universiti Teknikal Malaysia Melaka (UTeM). She received her B. Eng. in Medical Electronics (2001), Master Eng. in Telecommunications (2004) and PhD in Digital Image Processing (2015) from Universiti Teknologi Malaysia (UTM). Her research area involves Digital Image and Signal Processing, Computer Vision and Medical Imaging. She is registered with Board of Engineer Malaysia (BEM), Malaysia Board of Technologist (MBOT), Institute for Electrical and Electronics Engineers (IEEE) Signal Processing Society (SPS), IEEE Engineering in Medicine and Biology Society (EMBS) and International Association of Engineers (IAENG).

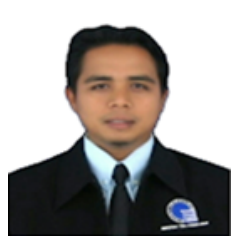

A. R. Abdullah received his B. Eng. in Electrical Engineering (2001), Master degree in Electrical Engineering (2004) and PhD degree in Power Engineering and Digital Signal Processing (2011) from Universiti Teknologi Malaysia (UTM). He is currently an Associate Professor in the Department of Power Electronics \& Drive, Faculty of Electrical Engineering, UniversitiTeknikal Malaysia Melaka (UTeM) andHead of AdvancedDigital Signal Processing (ADSP) Lab. He is currently active in the Center of Excellence $(\mathrm{CoE})$ andlead for E-Beca for UniversitiTeknikal Malaysia Melaka (UTeM). His field of specialization includes advanced digital signal processing for power quality, rehabilitation engineering, assistive technology and power electronics and drives.

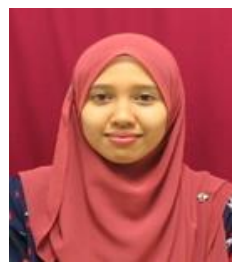

N. S. M. Noor received B. Eng of electronic and computer engineering from UniversitiTeknikal Malaysia Melaka (UTeM) in 2016. She is currently pursuig M. Sc degree in Electronic Engineering at UTeM.Her main research interest is in the field of image processing and machine learning.

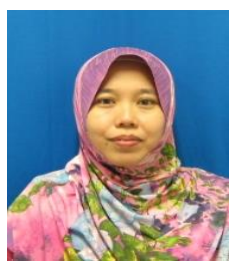

N. A. Hamid completed her Certificate and Diploma of Electrical Engineering (Power) from Politeknik Port Dickson Negeri Sembilan in 1992 and 1995 respectively. She obtained her B. Eng. Electrical (Power \& Control) from Hanyang Universiti, Ansan, South Korea in 1999. While working as Lecturer in Electrical Faculty, Universiti Teknologi Mara, Shah Alam she completed her Master of Electronic Engineering (Communication \& Computer) from Universiti Kebangsaan Malaysia in 2004. In 2014, she received her $\mathrm{PhD}$ from the same university specialist in Micro and Nanotechnology. Currently, she serves as a Senior Lecturer at Computer Department, Faculty of Electronic and Computer Engineering, Universiti Teknikal Malaysia Melaka. Her main research interest is renewable energy, actuator, sensor and MEMS devices.

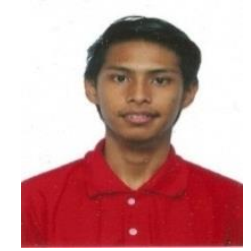

M. A. Muhammad Syahmi received Dip in Electronics Engineering from the Universiti Teknikal Malaysia Melaka (UTeM) from 2016. He is currently pursuing B.Eng in Electronic Engineering at UniversitiTeknikal Malaysia Melaka. His main research interest is in the field of robotic. 